\title{
Experimental investigation of free vibration analysis on fibre metal composite laminates
}

\author{
M. N. M. Merzuki ${ }^{1 *}$, M. R. M. Rejab ${ }^{1,2}$, M. S. M. Sani ${ }^{3}$, Bo Zhang ${ }^{2}$, Ma Quanjin ${ }^{1,2}$ \\ ${ }^{1}$ Structural Materials \& Degradation Focus Group, Faculty of Mechanical Engineering, \\ Universiti Malaysia Pahang, 26600 Pekan, Pahang, Malaysia \\ "Email: mubinmerzuki@gmail.com \\ ${ }^{2}$ School of Mechanical Engineering, Ningxia University, 750021 Yinchuan, China \\ ${ }^{3}$ Advanced Structural Integrity and Vibration Research Group, Faculty of Mechanical \\ Engineering, Universiti Malaysia Pahang, 26600 Pekan, Pahang, Malaysia
}

\begin{abstract}
Fibre-metal laminates (FMLs) offer advanced improvements over current available structural materials due to the excellent mechanical properties. In this work, the dynamic behaviour of the carbon fibre/epoxy, glass fibre/epoxy, aluminium 2024-T0, and fibre metal laminates were carried out. Furthermore, the different type of reinforced composites in FMLs and the effect of the layer sequence of metal layers were investigated. The composite laminates have been manufactured by a hot press machine. The free vibration tests were conducted to determine the dynamic characteristics of the samples. The accuracy of the experimental results was verified by comparing the numerical analysis results. The results indicate that the effect of thickness and the layer sequences of metal layers have a significant effect on the natural frequency of the FMLs.
\end{abstract}

Keywords: FMLs; natural frequency; free vibration analysis; dynamic characteristics; finite element analysis.

\section{INTRODUCTION}

Over the last decade, demand for lightweight materials caused many automakers to find alternative materials to replace the traditional materials like steel and cast iron in order to reduce the weight of the vehicle. By looking of composite materials widely used in aerospace due to high specific properties in term of strength to weight and stiffness to weight ratio, many automakers switching used composite materials in the automotive industry to replaced current materials to manufactured parts such as bulkheads, hood and B-pillar [1-4]. Laminated composites are an advanced class of materials formed by combining one or more materials that having different chemical and physicals properties.

Fibre metal laminates (FML) [5-9] consists of alternating layers of fibre reinforced polymer composites and metal alloys $[10,11]$. FMLs have improved resistance to impacts and environmental conditions due to the outer aluminium alloy layers [12-15]. Until now, FML is most popular and it is presently used for manufacturing of most part of aerospace structural component such as the aircraft engine cowlings, cargo floor and containers and seamless tube. In any structural service are frequency subjected to dynamics load. Therefore, 
FMLs need more sophisticated analysis and experiment to estimate the dynamic behaviour accurately. For the determination of the natural frequency and mode shape, analysis of free vibrations can be applied [16-23]. Nowadays, various experimental methods potentially applicable to determine dynamic behaviour (free vibration, rotating-beam deflection, forced vibration response, continuous wave or pulse propagation technique) have been used [2427]. The vibration response of the FML annular plate by combining different quadrature method was investigated by Rahimi et al. [28]. However, their focus study is confined to circular plates only. The linear and nonlinear free vibration of FML rectangular plates was investigated by Shooshtari and Razavi [29] using the Galerkin method. They have presented only on analytical results on FML. Another study by Tao et al. [30] analytical method, the author investigated the nonlinear dynamics behaviour of FML beam under moving load subjected to the thermal environment using Euler-Bernoulli beam hypothesis and Von Karman geometric nonlinear theory. It found that most studies on the dynamics behaviour of FML using various analytical studies. For dynamic behaviour of FML plate shows very few studies are available.

The aim of this study is focused on the investigation of the dynamic behaviour of FML materials. In this study, a free vibration test by impact hammer is used to obtain the mode shapes and natural frequency. The different type of reinforced composites in FMLs and the effect of the layer sequence of metal layers are investigated. In addition, the numerical analysis by a three-dimensional finite element model was developed using finite element anaylis (FEA) ABAQUS software. It is used to carry out a comparative study between numerical and experimental results.

\section{MATERIALS AND METHOD}

\section{Materials Preparation}

Glass fibre/epoxy (GF-E), carbon fibre/epoxy (CF-E) and an aluminium 2024-T0 are used for the fibre metal laminates manufacture. The mechanical properties of composite laminates and aluminium alloy are provided in Table 1 and 2, respectively. The aluminium (Al) surfaces were prepared for adhesive bonding by mechanical treatment using sandblasting to produce a macro-roughened surface, different roughness levels of the surface textures and to remove an undesirable oxide layer, which has been improved bonding durability [31-33].

Table 1. Properties of the materials used to produce fibre metal laminates (a) and (b);

(a) Properties of the Glass fibre/epoxy (GF-E) and carbon fibre/epoxy (CF-E)

\begin{tabular}{rcc}
\hline Property & GF-E & CF-E \\
\hline Longitudinal elastic modulus, $\mathrm{E}_{1}(\mathrm{GPa})$ & 7 & 17.5 \\
Transverse elastic modulus, $\mathrm{E}_{2}(\mathrm{GPa})$ & 7 & 17.5 \\
Thickness elastic modulus, $\mathrm{E}_{3}(\mathrm{GPa})$ & $1^{*}$ & $5^{*}$ \\
In-plane Poisson's ratio, $v_{12}$ & 0.22 & 0.24 \\
Thickness Poisson's ratio, $v_{13}, v_{23}$ & 0.22 & 0.24 \\
In-plane shear modulus, $\mathrm{G}_{12}(\mathrm{GPa})$ & $1^{*}$ & $2^{*}$ \\
Thickness shear modulus, $\mathrm{G}_{13}, \mathrm{G}_{23}(\mathrm{GPa})$ & 2.5 & 10.5 \\
\hline
\end{tabular}

Data taken from references 
Table 2. Properties of an aluminium 2024-T0 (Al)[34].

\begin{tabular}{rr}
\hline Property & Value \\
\hline Density, $\rho\left(\mathrm{kg} / \mathrm{m}^{3}\right)$ & 2780 \\
Young's modulus, E $(\mathrm{GPa})$ & 70.6 \\
Poisson ratio, $v$ & 0.3 \\
\hline
\end{tabular}

In the production process, fibre and aluminium alloys were cut in dimensions of 250 $\mathrm{mm} \times 25 \mathrm{~mm}$. Fibre-metal composite laminates were manufactured by application of epoxy resin to fibre layer and aluminium surface. During the experiment, free plate length is kept on $223 \mathrm{~mm}$.

\section{Fibre-Metal Composites Laminate Preparation}

The fibre metal composite laminate was prepared by stacking laminae and the aluminium sheet. The sequence lay-up of the composites of $2 / 1$ and $3 / 2$, as shown in Table 3 . The hand lay-up of the fibre metal laminates materials was made as shown in Figure 2. After the layup process, the compression machines are used to compress and applied pressure $0.4 \mathrm{MPa}$ under room temperature, shown in Figure 3.

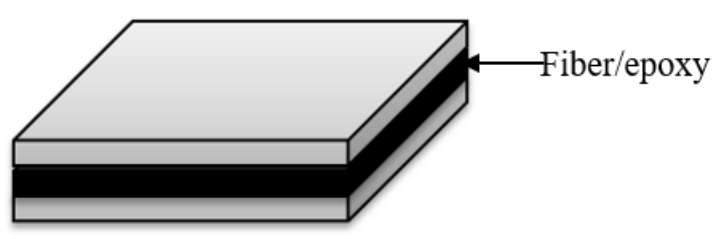

(a)

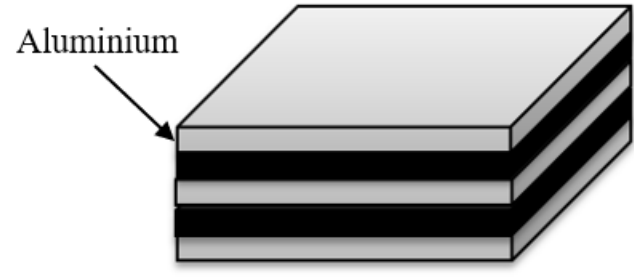

(b)

Figure 2. Configuration of the fiber/metal/epoxy composite laminates (a) $2 / 1$, (b) $3 / 2$

Table 3. Stacking sequence of the fibre metal laminates composite (FML).

\begin{tabular}{ccc}
\hline Naming & Stacking sequence & Configurations \\
\hline $\mathrm{H} 1$ & $\mathrm{Al} / \mathrm{GF}-\mathrm{E} / \mathrm{Al}$ & $2 / 1$ \\
$\mathrm{H} 2$ & $\mathrm{Al} / \mathrm{CF}-\mathrm{E} / \mathrm{Al}$ & $2 / 1$ \\
$\mathrm{H} 3$ & $\mathrm{Al} / \mathrm{GF}-\mathrm{E} / \mathrm{AL} / \mathrm{GF}-\mathrm{E} / \mathrm{Al}$ & $3 / 2$ \\
$\mathrm{H} 4$ & $\mathrm{Al} / \mathrm{CF}-\mathrm{E} / \mathrm{Al} / \mathrm{CF}-\mathrm{A} / \mathrm{Al}$ & $3 / 2$ \\
\hline AL: Aluminium; GF-E: Glass fiber/epoxy; CF-E: Carbon fiber/epoxy
\end{tabular}




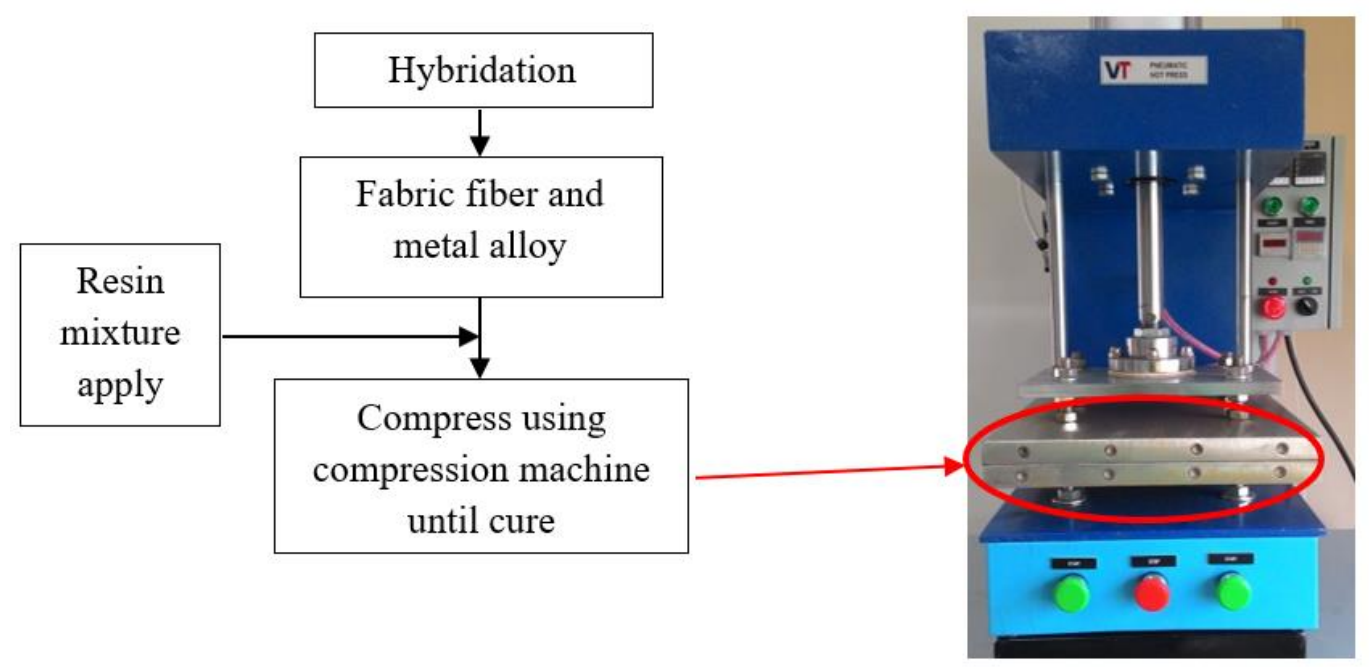

Figure 3. Fiber metal composite laminates preparation process.

\section{Experiment Modal Analysis (EMA) Setup}

Dynamic characteristic of fibre metal composites laminates was measured using the free vibration method as per the ASTM standard E756. Figure 4 shows the experiment setup for free vibration test set up. In this experiment, uniaxial accelerometer, Piezotronic hammer and National Instrument and Vibration Data Logger were used for output signal acquisition, stimulus forces signal and data acquisition. To achieve dynamic characteristic, all specimens were excited by an impact hammer. Frequency response properties of the samples were recorded during the dynamic modal analysis test a function of amplitude and frequency $(\mathrm{Hz})$ by using Fast Fourier Transforms (FFT) in order to determine the natural frequency. The test parameters were analyses of $1000 \mathrm{~Hz}$.

Table 4. Dimension and weight of specimens used in the experiment.

\begin{tabular}{cccc}
\hline Specimen ID & Length $(\mathrm{mm})$ & Width $(\mathrm{mm})$ & Thickness $(\mathrm{mm})$ \\
\hline CF-E & 250 & 25 & 1.34 \\
GF-E & 250 & 25 & 2.56 \\
Al & 250 & 25 & 0.88 \\
H1 & 250 & 25 & 2.32 \\
H2 & 250 & 25 & 2.04 \\
H3 & 250 & 25 & 3.50 \\
H4 & 250 & 25 & 3.18 \\
\hline
\end{tabular}




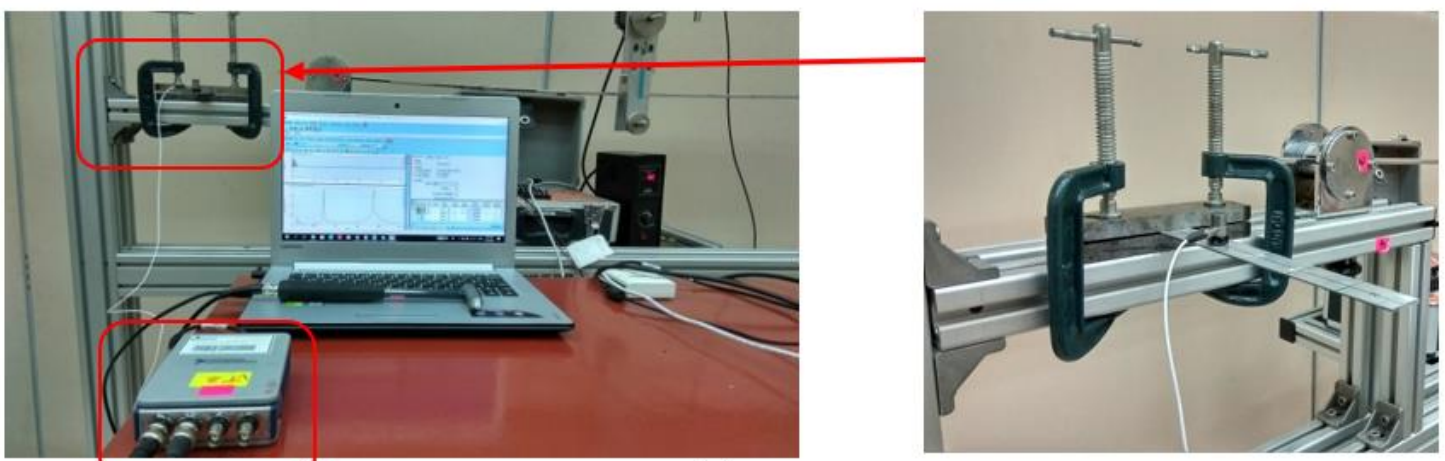

(a)

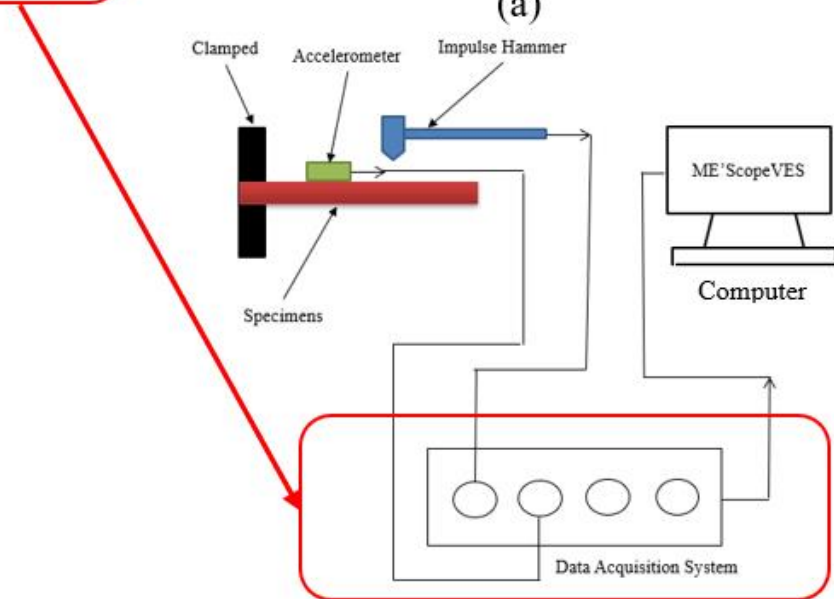

(b)

Figure 4. Experimental setup: (a) Experimental overview, (b) Schematic diagram of free vibration testing setup.

Vibration test specimens with a dimension of $250 \mathrm{~mm} \times 25 \mathrm{~mm}$ were prepared and specimens were clamped by supports, shown in Figure 5. The specimen dimensions follow ASTM E756. Table 4 shows the dimension of the plate for vibration tests. In this experiment, the uniaxial accelerometer will move to every point while impact hammer will only impact at one point only (point $\mathrm{d}$ ). The process called roving accelerometer. Fifteen averages data which are obtained from excited location are taken during acquisition for each specimen to prevent experimental errors.

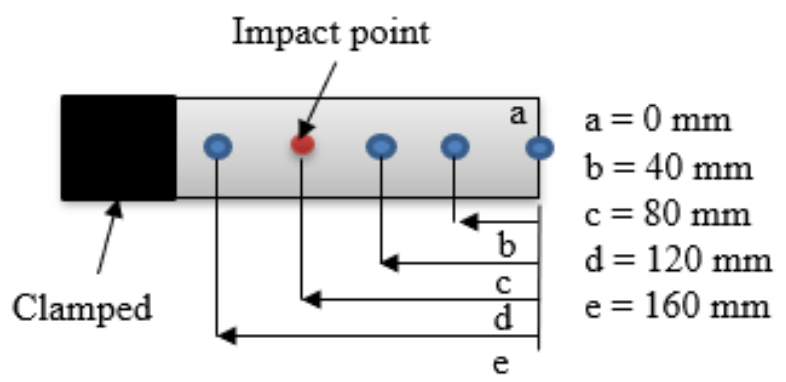

Figure 5. Position of impact and uniaxial accelerometer points. 


\section{Finite Element Analysis (FEA) Setup}

In the numerical analysis, a solid homogeneous model is used in the modelling of FMLs. The three rotations and displacements are constrained at the FMLs as showed in Figure 6. The FMLs are represented with the 3-D linear solid element (C3D8R) of ABAQUS. C3D8R means an 8-node linear brick and reduced integration. The number of elements used in the analysis was 1992 and the number of nodes is 3024. Linear perturbation and Lanczos method are used to extract Eigenvalues of the first three modes.

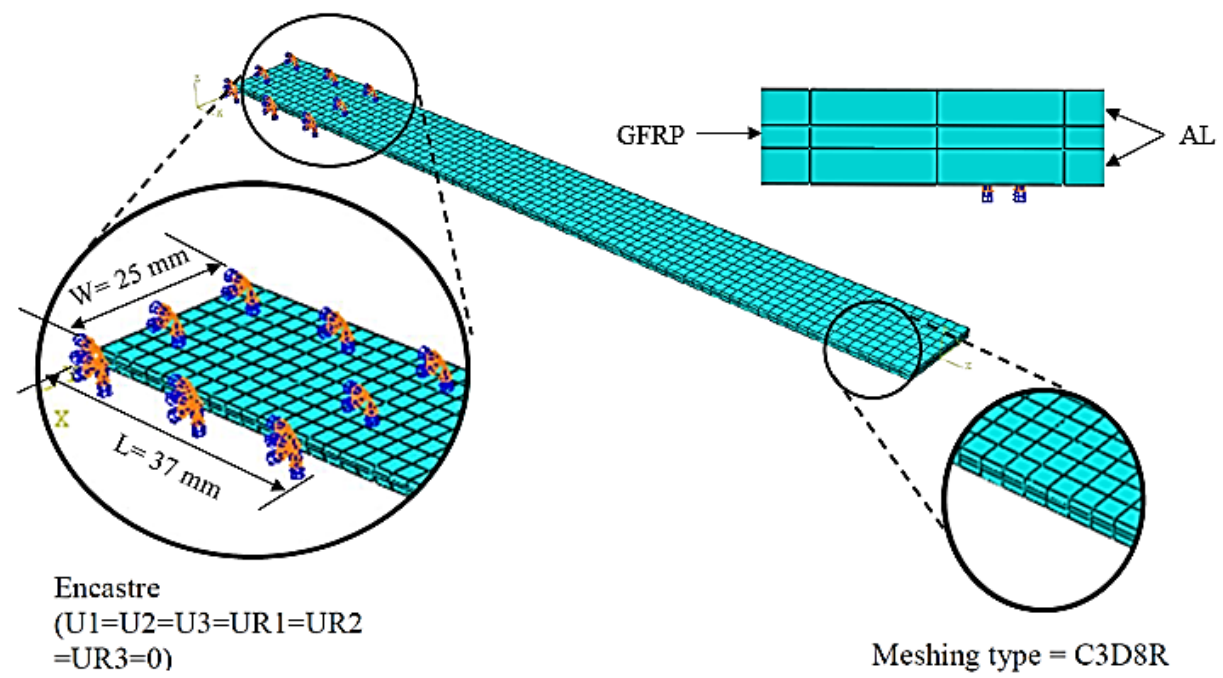

Figure 6. Boundary conditions for frequency analyses in ABAQUS.

\section{RESULTS AND DISCUSSION}

The frequency response values were recorded after the vibration test and then tabulated in Table 5.

Table 5. Frequency values of materials analysed between experiment and numerical method.

\begin{tabular}{cccccccccc}
\hline & \multicolumn{3}{c}{ Mode 1 (Hz) } & \multicolumn{3}{c}{ Mode 2 (Hz) } & \multicolumn{3}{c}{ Mode 3 (Hz) } \\
\hline Specimens & Exp & Numerical & $\begin{array}{c}\text { Error } \\
\text { (\%) }\end{array}$ & Exp & Numerical & $\begin{array}{c}\text { Error } \\
(\boldsymbol{\%})\end{array}$ & Exp & Numerical & $\begin{array}{c}\text { Error } \\
(\boldsymbol{\%})\end{array}$ \\
\hline CF-E & 11.70 & 13.69 & 17.59 & 105.00 & 109.14 & 3.94 & 309.00 & 305.20 & 1.22 \\
GF-E & 20.20 & 18.25 & 9.61 & 132.00 & 125.11 & 5.21 & 382.00 & 364.33 & 4.71 \\
Al & 13.40 & 16.21 & 17.33 & 95.00 & 101.62 & 6.96 & 259.00 & 283.03 & 8.50 \\
H1 & 29.03 & 30.42 & 4.79 & 187.00 & 190.28 & 1.75 & 525.00 & 532.25 & 1.38 \\
H2 & 21.50 & 25.64 & 16.14 & 159.00 & 160.63 & 1.02 & 458.00 & 450.01 & 1.74 \\
H3 & 48.64 & 50.78 & 4.21 & 298.00 & 303.66 & 1.08 & 871.00 & 845.58 & 2.91 \\
H4 & 41.77 & 41.59 & 0.40 & 266.00 & 260.35 & 2.12 & 716.00 & 722.84 & 0.95 \\
\hline \multicolumn{2}{r}{ Exp: Experiment } & & & & & & & &
\end{tabular}




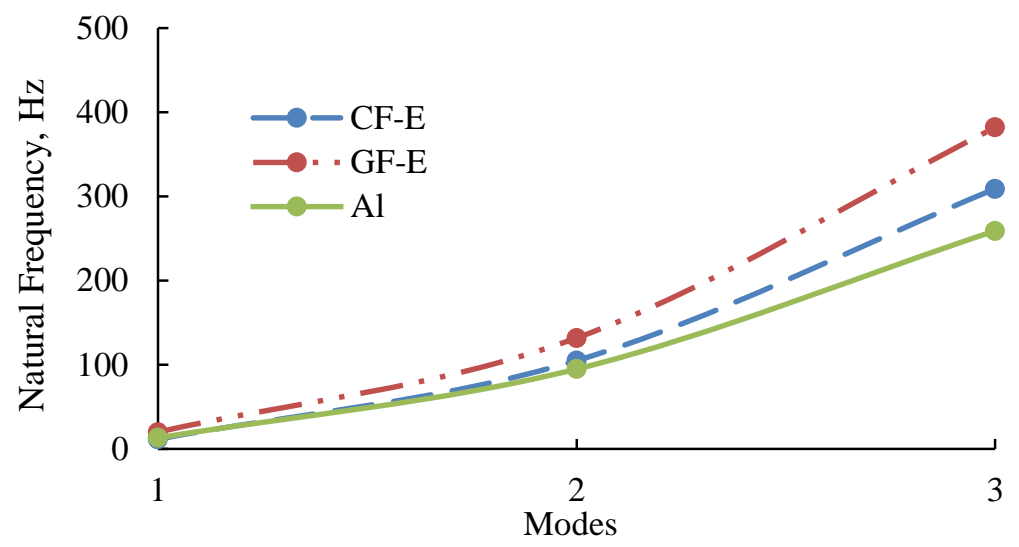

(a)

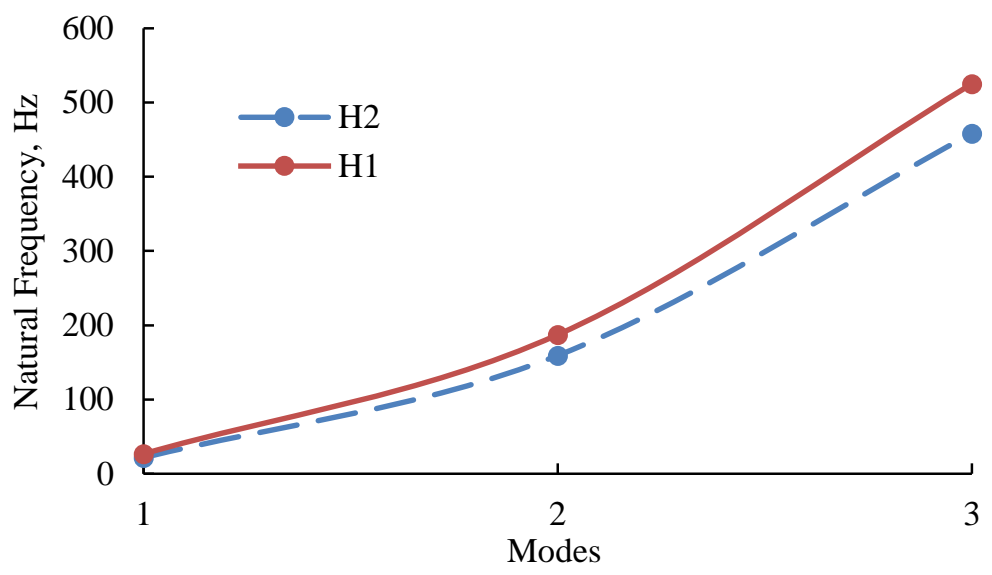

(b)

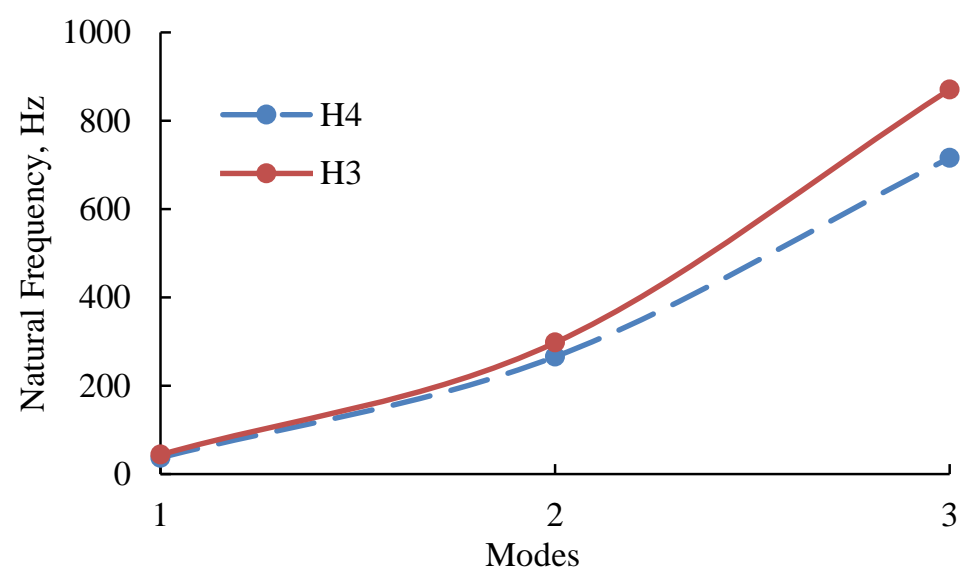

(c)

Figure 7. Variation of the first, second and third mode of natural frequency based on experimental result, (a) GF-E, CF-E, and A1, (b) H1 and H2, and (c) H3 and H4. 
Table 5 showed the different results of natural frequency value from the experiment and numerical results. In this experiment, the different type of reinforced composites in FMLs and the effect of the layer sequence of metal layers are investigated. To study the effect of different type reinforced composite in FMLs, two types of reinforced composite materials used which is CF-E and GF-E. The thickness varied between two different types of reinforced composite materials, by keeping the length and wide constant (250 $\mathrm{mm}$ x $25 \mathrm{~mm})$, as shown in Table 4. The results showed that natural frequency of GF-E composite was seemingly greater that CF-E composite, showed in Figure 7. The first three modes of natural frequency $\mathrm{H} 1$ and H2, are $29.03 \mathrm{~Hz}, 187 \mathrm{~Hz}$ and $525 \mathrm{~Hz}$; and $21.50 \mathrm{~Hz}, 159 \mathrm{~Hz}$ and $458 \mathrm{~Hz}$. The higher first natural frequency value is $\mathrm{H} 1$ due to the thickness of GF-E more than others. It observed that dissimilar thickness shows significantly influence the natural frequency of the FMLs.

Table 6. The first three mode shape between EMA and FEA analysis for H1.

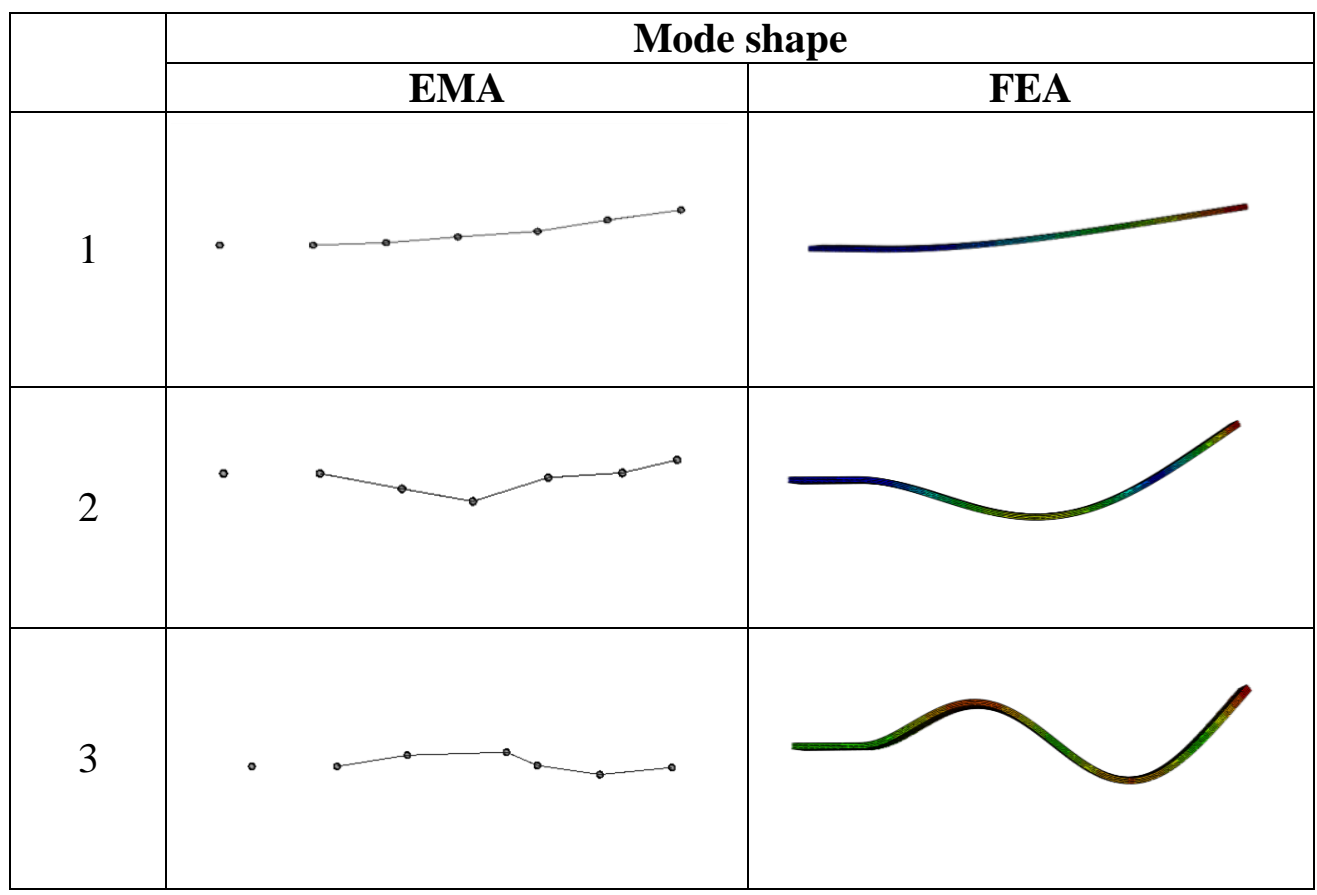

Effect of the layer sequence of metal layers in composite materials plate (CF-E and GF-E) shows the natural frequency increases as more the Al plate embedded in the composite materials plate. Table 4.6 (c) shows the first mode of the natural frequency of $\mathrm{H} 4$ and $\mathrm{H} 3$ are $41.77 \mathrm{~Hz}$ and $50.78 \mathrm{~Hz}$. It can be observed that the when Al plate embedded in the middle composite layer in $\mathrm{H} 4$ shows significantly influence the natural frequency which is increase from $\mathrm{H} 2$ where $21.50 \mathrm{~Hz}$ to $41.77 \mathrm{~Hz}$. The percentage of increment is $42.67 \%$. For $\mathrm{H} 1$ to $\mathrm{H} 3$ is $40.18 \%$. This was because of the lateral stiffness of Al layers more than composite materials ones. Table 6 shows the first three mode shapes using a between EMA and FEA analysis for H1. Good adaptions could be observed between results. 


\section{CONCLUSIONS}

The mode shapes and natural frequency of aluminium 2024-TO alloy, glass fibre/epoxy (GFE), carbon fibre/epoxy (CF-E), and fibre metal laminates (FML) composite were investigated. Vibration characteristic of all samples was determined by free vibration analysis using the exciting impact hammer on the specimen. Two factors are carried out which is the different type of reinforced composites in FMLs and the effect of the layer sequence metal layer. Based on the conducted experiments and numerical analysis, the following conclusions were made. The numerical agree well with their experiment results. The natural frequency shows differ between two types reinforced composite in FML which is CF-E and GF-E. With the thickness of glass fibre ply used in this experiment thicker compares to carbon fibre ply, shows significantly influence the natural frequency. The natural frequency of the FMLs plate increase when more $\mathrm{Al}$ layers embedded in the composite layer.

\section{ACKNOWLEDGEMENTS}

The authors are grateful of the Ministry of Higher Education Malaysia and Universiti Malaysia Pahang for funding this research PGRS1703108 and RDU180397 and also gratefully acknowledge supports for this work from the Key technology R\&D project of Ningxia (Grant No. 2018BFH03001) and the Graduate Innovation Education Project of Ningxia (Grant No.YKC201606).

\section{REFERENCES}

[1] Wheatley A, Warren D, Das S. Development of low-cost carbon fibre for automotive applications. Advanced Composite Materials for Automotive Applications: Structural Integrity and Crashworthiness. 21014;51-73.

[2] Vlot A. Glare: History of the development of a new aircraft material. Springer Science \& Business Media, 2001.

[3] Lei X, Rui W, Shujie Z, Yong L. Vibration characteristics of glass fabric/epoxy composites with different woven structures. Journal of Composite Materials. 2011;45:1069-1076.

[4] Rayhan S. A comprehensive study on the buckling behaviour of woven composite plates with major aerospace cutouts under uniaxial loading. Journal of Mechanical Engineering and Sciences. 2019;13:4756-4776.

[5] Sinmazçelik T, Avcu E, Bora MÖ, Çoban O. A review: Fibre metal laminates, background, bonding types and applied test methods. Materials \& Design. 2011;32:3671-3685.

[6] Iriondo J, Aretxabaleta L, Aizpuru A. Characterisation of the elastic and damping properties of traditional FML and FML based on a self-reinforced polypropylene. Composite Structures. 2015;131:47-54.

[7] Mohammed I, Talib ARA, Sultan MTH, Jawaid M, Ariffin AH, Saadon S. Mechanical properties of fibre-metal laminates made of natural/synthetic fibre composites. BioResources. 2018;13;2022-2034. 
[8] Huang Y, Liu J, Huang X, Zhang J, Yue G. Delamination and fatigue crack growth behavior in Fiber Metal Laminates (Glare) under single overloads. International Journal of Fatigue. 2015;78:53-60.

[9] Balci M, Nalbant MO, Kara E, Gündogdu Ö. Free vibration analysis of a laminated composite beam with various boundary conditions. International Journal of Automotive and Mechanical Engineering. 2014;9:1734.

[10] Rajkumar G, Krishna M, Narasimhamurthy H, Keshavamurthy Y, Nataraj J. Investigation of tensile and bending behavior of aluminum based hybrid fiber metal laminates. Procedia Materials Science. 2014;5:60-68.

[11] Ahmadi H, Liaghat G, Sabouri H, Bidkhouri E. Investigation on the high velocity impact properties of glass-reinforced fiber metal laminates. Journal of Composite Materials. 2013;47:1605-1615.

[12] Ghasemi AR, Mohandes M. Free vibration analysis of rotating fiber-metal laminate circular cylindrical shells. Journal of Sandwich Structures \& Materials, 2017;9:6372.

[13] Tooski MY, Alderliesten R, Ghajar R, Khalili S. Experimental investigation on distance effects in repeated low velocity impact on fiber-metal laminates. Composite Structures. 2013;99:31-40.

[14] Tsamasphyros GJ, Bikakis GS. Analytical modeling to predict the low velocity impact response of circular GLARE fiber-metal laminates. Aerospace Science and Technology. 2013;29:28-36.

[15] Merzuki M, Rejab M, Sani M, Zhang B, Quanjin M, Rafizi W. Investigation of modal analysis on glass fiber laminate aluminium reinforced polymer: An experimental study. IOP Conference Series: Materials Science and Engineering. 2019;469:012065.

[16] Černý M, Glogar P, Manocha LM. Resonant frequency study of tensile and shear elasticity moduli of carbon fibre reinforced composites (CFRC). Carbon. 2000;38:2139-2149.

[17] Zhang P, Ruan J, Li W. Influence of some factors on the damping property of fiberreinforced epoxy composites at low temperature. Cryogenics. 2001;41:245-251.

[18] El-Mahdy T, Gadelrab R. Free vibration of unidirectional fiber reinforcement composite rotor, ed: Academic Press, 2000.

[19] Kim MT, Rhee KY, Jung I, Park SJ, Hui D. Influence of seawater absorption on the vibration damping characteristics and fracture behaviors of basalt/CNT/epoxy multiscale composites. Composites Part B: Engineering. 2014;63:61-66.

[20] Treviso A, Van Genechten B, Mundo D, Tournour M. Damping in composite materials: Properties and models. Composites Part B: Engineering. 2015;78:144-152.

[21] Nayak N, Meher S, Sahu S. Experimental and numerical study on vibration and buckling characteristics of glass-carbon/epoxy hybrid composite plates. Proc. of Int. Conf. on Advances in Civil Engineering, AETACE. 2013;888-895.

[22] Palazzetti R, Zucchelli A, Trendafilova I. The self-reinforcing effect of Nylon 6, 6 nano-fibres on CFRP laminates subjected to low velocity impact. Composite Structures. 2013;106:661-671.

[23] Panda H, Sahu S, Parhi P. Hygrothermal effects on free vibration of delaminated woven fiber composite plates-numerical and experimental results Composite Structures. 2013;96:502-513. 
[24] Sarlin E et al. Vibration damping properties of steel/rubber/composite hybrid structures. Composite structures. 2012;94:3327-3335.

[25] Lou J, Wu L, Ma L, Xiong J, Wang B. Effects of local damage on vibration characteristics of composite pyramidal truss core sandwich structure," Composites part b: Engineering. 2014;62:73-87.

[26] Yan L, Chouw N, Jayaraman K. On energy absorption capacity, flexural and dynamic properties of flax/epoxy composite tubes. Fibers and Polymers. 2014;15:1270-1277.

[27] Chavan SS, Joshi M. Study on vibration analysis of composite plate. International journal of advances in Production and Mechanical Engineering. 2015;69-76.

[28] Rahimi GH, Gazor MS, Hemmatnezhad M, Toorani H. Free vibration analysis of fiber metal laminate annular plate by state-space based differential quadrature method. Advances in Materials Science and Engineering. 2014.

[29] Shooshtari A, Razavi S. A closed form solution for linear and nonlinear free vibrations of composite and fiber metal laminated rectangular plates. Composite Structures. 2010;92:2663-2675.

[30] Tao C, Fu Y-M, Dai H-L. Nonlinear dynamic analysis of fiber metal laminated beams subjected to moving loads in thermal environment. Composite Structures. 2016;140:410-416.

[31] Park SY, Choi WJ, Choi HS, Kwon H, Kim SH. Recent trends in surface treatment technologies for airframe adhesive bonding processing: a review (1995-2008). The Journal of Adhesion. 2010;86:192-221.

[32] Monden A, Sause M, Hartwig A, Hammerl C, Karl H, Horn S. Evaluation of surface modified CFRP-metal hybrid laminates. Euro Hybrid Materials and Structures. 2014;1-8.

[33] Harris A, Beevers A. The effects of grit-blasting on surface properties for adhesion. International Journal of Adhesion and Adhesives. 1999;19:445-452.

[34] Rejab M, Cantwell W. The mechanical behaviour of corrugated-core sandwich panels. Composites Part B: Engineering. 2013;47:267-277. 